\title{
EFEITO DA ADIÇÃO DE ARGININA EM DIFERENTES CONCENTRAÇÕES NA PROPRIEDADE QUIIMICA DA LIBERAÇÃO DE FLUORETO DE SELANTE DE FÓSSULAS E FISSURAS
}

\author{
Maria Fernanda M. Bicudo*, Mário Alexandre C. Sinhoreti, Maurício B. Guarda, Fernanda M. Pascon.
}

\section{Resumo}

O objetivo do presente estudo foi avaliar o efeito da adição de diferentes concentrações do aminoácido - Arginina- $L$ a um selante resinoso comercial na propriedade química da liberação de fluoreto do material. A amostra constituiu-se de espécimes de material selador distribuídos em 3 grupos: selante resinoso, selante resinoso $+5 \%$ de arginina e selante resinoso $+7 \%$ de arginina e 2 subgrupos de armazenamento: solução desmineralizante (DES) e remineralizante (RE) $(n=10)$. Após a adição da arginina, os espécimes foram preparados em matrizes de silicone $(6 \mathrm{~mm} \times 2 \mathrm{~mm})$ e imersos individualmente em $3 \mathrm{ml}$ nas soluções DES e RE, as quais foram avaliadas utilizando íon eletrodo específico quanto à liberação de fluoreto (em $\mu \mathrm{g} / \mathrm{mL} / \mathrm{ppm} \mathrm{F}$ ) nos tempos 1, 2, 3, 5, 7, 9, 12 e 30 dias. Os dados foram submetidos a testes de normalidade, ANOVA e teste Tukey ( $\alpha=5 \%)$.

\section{Palavras-chave:}

Arginina, Flúor, Selante de fossas e fissuras.

\section{Introdução}

Selantes de fóssulas e fissuras são aplicados na superfície dentária para impedir o crescimento do biofilme bloqueando a nutrição das bactérias (Splieth 2010), além de promover a liberação de flúor, que age como um componente remineralizante. Alguns agentes não fluoretados tem sido estudados como alternativa ao flúor. Entre esses agentes está a arginina que quando presente na cavidade oral pode ser metabolizada por determinadas bactérias e produzir amônia, que neutraliza ácido e aumenta o pH do biofilme oral (Nascimento e Burne, 2014). A adição de agentes antimicrobianos aos materiais resinosos poderia diminuir ou impedir a adesão de biofilme na superfície do material e assim evitar novos episódios de desmineralização dos tecidos dentários (Yoshida et al., 1999; Bürgers et al., 2009; de Fúcio et al., 2009; Aydin Sevinç e Hanley, 2010). O objetivo do presente estudo foi avaliar 0 efeito da adição de diferentes concentrações do aminoácido - Arginina- $L$ a um selante resinoso na propriedade química da liberação de fluoreto do material.

\section{Resultados e Discussão}

Metodologia:

1. Preparo de matrizes de silicone $(6 \mathrm{~mm} \times 2 \mathrm{~mm})$ e colocação de fio dental;

2. Pesagem, incorporação e homogeneização de $5 \%$ e

$7 \%$ de Arginina ao selante comercial;

3. Inserção dos materiais nas matrizes e fotoativação por 40 segundos;

4. Impermeabilização dos espécimes e armazenamento por 24 horas;

5. Imersão dos espécimes em $3,0 \mathrm{ml}$ das soluções DES (2,0 $\mathrm{mM}$ de cálcio, 2,0 $\mathrm{mM}$ de fosfato e $75 \mathrm{mM}$ de tampão acetato, $\mathrm{pH}=4,3)$ e $\mathrm{RE}(1,5 \mathrm{mM}$ de cálcio, 0,9 mM de fosfato, $150 \mathrm{mM}$ de cloreto de potássio, $20 \mathrm{mM}$ de tampão Tris, $\mathrm{pH}=7$ ).

6. Leitura da liberação de fluoreto nos tempos: 1, 2, 3, 5, $7,9,12$ e 30 dias.

Análise estatística: Os dados foram submetidos aos testes Shapiro-Wilk, Anova e Tukey $(p>0,05)$.
Tabela 1. Média $( \pm \mathrm{DP})$ dos valores de fluoreto liberados (em $\mu \mathrm{g} / \mathrm{mL}$-ppm F) na solução desmineralizadora

\begin{tabular}{cccc}
$\begin{array}{c}\text { TEMPOS } \\
\text { (Dias) }\end{array}$ & Controle & $\begin{array}{c}\text { GRUPOS } \\
\text { Arginina } 5 \%\end{array}$ & Arginina $7 \%$ \\
\hline 1 & $2.966 \pm 1.611 \mathrm{a}$ & $4.562 \pm 2.157 \mathrm{a}$ & $3.461 \pm 1.004 \mathrm{a}$ \\
2 & $1.088 \pm 0.725 \mathrm{~b}$ & $2.035 \pm 0.789 \mathrm{a}$ & $1.710 \pm 0.571 \mathrm{ab}$ \\
3 & $1.122 \pm 1.555 \mathrm{~b}$ & $1.642 \pm 0.656 \mathrm{a}$ & $1.421 \pm 0.529 \mathrm{a}$ \\
5 & $1.494 \pm 0.599 \mathrm{~b}$ & $3.470 \pm 0.960 \mathrm{a}$ & $3.275 \pm 0.914 \mathrm{a}$ \\
7 & $1.700 \pm 0.678 \mathrm{~b}$ & $3.571 \pm 0.722 \mathrm{a}$ & $3.396 \pm 0.961 \mathrm{a}$ \\
9 & $1.251 \pm 0.524 \mathrm{~b}$ & $2.695 \pm 0.469 \mathrm{a}$ & $2.514 \pm 0.624 \mathrm{a}$ \\
12 & $1.859 \pm 0.710 \mathrm{~b}$ & $3.771 \pm 0.910 \mathrm{a}$ & $3.586 \pm 0.967 \mathrm{a}$ \\
30 & $5.636 \pm 1.476 \mathrm{~b}$ & $10.703 \pm 4.201 \mathrm{a}$ & $10.237 \pm 4.657 \mathrm{a}$ \\
\hline
\end{tabular}
estudados para cada tempo de análise

Tabela 2. Média ( $\pm \mathrm{DP})$ dos valores de fluoreto liberados (em $\mu \mathrm{g} / \mathrm{mL}-\mathrm{ppm} \mathrm{F}$ ) na solução Remineralizadora (RE)

TEMPOS GRUPOS

\begin{tabular}{cccc} 
(Dias) & Controle & Arginina $5 \%$ & Arginina $7 \%$ \\
\hline 1 & $4.678 \pm 3.037 \mathrm{a}$ & $3.265 \pm 1.574 \mathrm{a}$ & $3.497 \pm 1.426 \mathrm{a}$ \\
2 & $1.156 \pm 0.703 \mathrm{a}$ & $1.501 \pm 0.310 \mathrm{a}$ & $1.889 \pm 0.937 \mathrm{a}$ \\
3 & $0.922 \pm 0.490 \mathrm{~b}$ & $1.343 \pm 0.343 \mathrm{ab}$ & $1.576 \pm 0.639 \mathrm{a}$ \\
5 & $1.635 \pm 0.776 \mathrm{~b}$ & $2.890 \pm 0.880 \mathrm{a}$ & $3.196 \pm 1.335 \mathrm{a}$ \\
7 & $1.779 \pm 0.890 \mathrm{~b}$ & $2.761 \pm 0.845 \mathrm{a}$ & $3.234 \pm 1.357 \mathrm{a}$ \\
9 & $1.570 \pm 0.567 \mathrm{~b}$ & $2.141 \pm 0.689 \mathrm{ab}$ & $2.272 \pm 1.154 \mathrm{a}$ \\
12 & $2.305 \pm 1.098 \mathrm{a}$ & $2.961 \pm 1.015 \mathrm{a}$ & $3.279 \pm 1.460 \mathrm{a}$ \\
30 & $6.145 \pm 3.584 \mathrm{a}$ & $8.032 \pm 2.948 \mathrm{a}$ & $8.165 \pm 3.308 \mathrm{a}$
\end{tabular}

Letras minúsculas iguais em linhas representam ausência de diferença estatística entre os grupos estudados para cada tempo de análise

\section{Conclusões}

Concluiu-se que a adição de Arginina ao selante comercial aumentou a liberação de fluoreto para todos os tempos estudados quando na solução DES e até o $7^{\circ}$ dia quando na solução RE.

\section{Agradecimentos}

Ao PIBIC/Unicamp pela bolsa de estudos concedida e ao Marcelo Maistro do Departamento de Odontologia Infantil pelo apoio no treinamento e condução das análises. 